\title{
Increase in mucociliary clearance in normal man induced by oral high frequency oscillation
}

\author{
RJD GEORGE, MA JOHNSON, D PAVIA, JE AGNEW, SW CLARKE, DM GEDDES \\ From the London Chest Hospital and The Royal Free Hospital, London
}

ABSTRACT Data on the effect on mucociliary clearance of oral high frequency oscillation is conflicting. By means of a technique to superimpose high frequency oscillation on tidal breathing, changes in mucociliary clearance during high frequency oscillation were studied in seven normal non-smokers by monitoring the clearance of inhaled radiolabelled aerosol from the lungs. After inhalation of $5 \mu \mathrm{m}$ technetium $99 \mathrm{~m}$ labelled particles under controlled conditions, whole lung clearance was monitored by scintillation counters half hourly for six hours with a final count at 24 hours, from which tracheobronchial deposition and clearance could be calculated. Control and high frequency oscillation studies were performed on separate days in random order. Oral high frequency oscillation was applied by a bass loudspeaker through a mouthpiece to superimpose sinewave oscillations (RMS input pressure $1.2 \mathrm{~cm} \mathrm{H}_{2} \mathrm{O}$, mean pressure zero) on normal breaths. On high frequency oscillation days 30 minutes of oscillation alternated with 30 min of rest. Between 3 and 4.5 hours mucociliary clearance with high frequency oscillation exceeded control by about $10 \%(\mathrm{p}<0.05)$. The mean time taken to eliminate $90 \%$ of deposited radioaerosol from the tracheobronchial tree fell from 4 hours 50 minutes (range $1 \mathrm{~h} 52 \mathrm{~min}-6 \mathrm{~h} 50 \mathrm{~min}$ ) during control to 3 hours 43 minutes (range $2 \mathrm{hr} 28 \mathrm{~min}-5 \mathrm{hr} 54 \mathrm{~min}$ ) during the high frequency oscillation run $(p<0.05)$. Possibly this comfortable, simple technique would be of therapeutic benefit to patients with chronic sputum retention and merits further investigation.

Mucociliary clearance within the lungs is an important host defence mechanism operating between the terminal bronchioles and the trachea to clear inhaled and locally produced debris. Its effectiveness depends on the composition and characteristics of the mucus coupled with the beating of the underlying cilia. In the central airways mucociliary clearance is augmented by cough. Means of improving mucociliary clearance in disease have been based largely on modification of the characteristics of the mucus or increasing ciliary beat frequency, or both. Pharmacological intervention has met with relatively limited success ${ }^{\prime}$ and effective physiotherapy remains the mainstay of treatment in patients with sputum retention. ${ }^{2}$ Vibration and percussion during conventional physiotherapy may act either by propelling the mucus into the larger airways or by altering mucus characteristics, which are known to

Address for reprint requests: Dr RJD George, London Chest Hospital, London E2 9JX.

Accepted 23 January 1985 change with vibration at various frequencies. ${ }^{34}$

In high frequency ventilation gas oscillates in the airways at frequencies of up to $30 \mathrm{~Hz}$ and it is now established as an alternative to intermittent positive pressure ventilation. Apart from the effects on gas exchange, several workers have reported changes in mucociliary clearance with various types of high frequency ventilation; but the results are conflicting and depend on the technique used..$^{4-7}$ Using a technique we have recently developed for superimposing oral high frequency oscillations on normal tidal breathing $^{8}$ we have investigated the effects of high frequency oscillation on mucociliary clearance is unsedated, normal subjects.

\section{Methods}

We studied seven healthy, non-smoking volunteers (four male, three female; mean age 26, range 21-31 years). All had normal lung function as assessed by spirometry (Vitalograph), peak flow (Wright), and flow volume loops (Ohio) (table). Each subject 
Indices of lung function and radioaerosol delivery (means and ranges) before control study and high frequency ventilation (HFV) study of tracheobronchial clearance

\begin{tabular}{lll}
\hline & Control & $H F V$ \\
\hline FEV (\% pred) & $110(94-131)$ & $115(100-130)$ \\
FVC (\% pred) & $110(96-123)$ & $109(88-124)$ \\
PEFR (\% pred) & $102(93-109)$ & $100(88-109)$ \\
FEF 25-75 (\% pred) & $80(58-104)$ & $88(58-109)$ \\
Average inspiratory flow $\left(1\right.$ min $\left.^{-1}\right)$ & $22(19-24)$ & $28(11-42)$ \\
Alveolar deposition (\%) & $54(40-68)$ & $49(27-69)$ \\
Penetration index & $0.71(0.50-0.91)$ & $0.66(0.45-0.90)$ \\
\hline
\end{tabular}

FVC - forced vital capacity; PEFR - peak expiratory flow rate; FEF $25-75$-forced expiratory flow between expiration of $25 \%$ and $75 \%$ of vital capacity.

underwent a control study and an oral high frequency oscillation study in random order on separate days.

Oral high frequency oscillation were superimposed on tidal breathing with a $20 \mathrm{~cm}$ bass loudspeaker. This was encased to deliver sine waves down a $50 \mathrm{~cm}$ tube (internal diameter $2.5 \mathrm{~cm}$ ) attached to a mouthpiece (fig 1). A side arm in the tube was connected to a warm water humidifier. To achieve maximum oscillatory flow within the lung oscillations were applied in each case at apparent respiratory system resonance (mean $10 \mathrm{~Hz}$, range 8-12 Hz). Choice of resonant frequency was determined by the subjects themselves, who indicated the frequency at which the sensation of shaking within the chest was maximum. Previous studies have confirmed that this conforms closely to respiratory system resonance. ${ }^{4}$

Mucociliary clearance was measured with an objective radioaerosol technique. The technique has

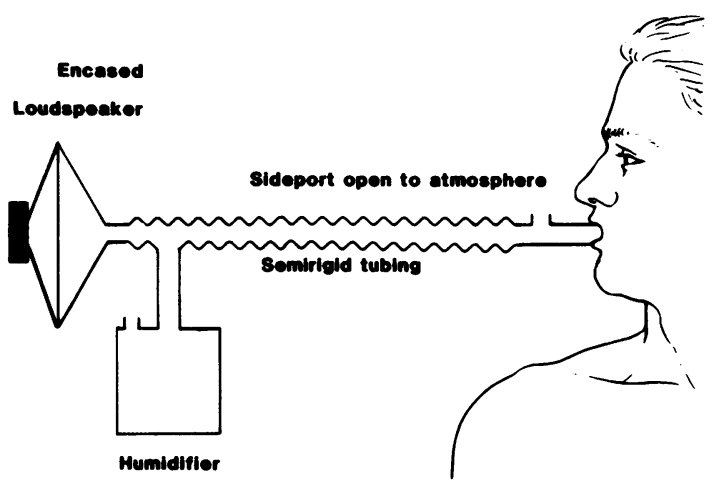

Fig 1 Arrangement for delivering oral high frequency oscillation. A sinewave generator and amplifier drive a $20 \mathrm{~cm}$ bass loudspeaker at a predetermined frequency. The loudspeaker is encased to deliver the oscillations down a $50 \mathrm{~cm}$ length of semirigid tubing attached to a mouthpiece. Just distal to the mouthpiece is a $1.5 \mathrm{~cm}$ diameter sideport open to atmosphere. A further sideport is attached to a warm water humidifier. been described in full. ${ }^{10}$ Monodisperse polystyrene particles (diameter $5 \mu \mathrm{m}$ ) labelled unleachably with a gamma emitting radionuclide, technetium $99 \mathrm{~m}$, were inhaled by the volunteer subjects via the mouth under strictly controlled conditions. The initial topographical distribution of deposited radioaerosol in both lungs was ascertained by gamma camera with a wide field of view. The subjects' lungs were also viewed after the inhalation of krypton $81 \mathrm{~m}$ to outline the lung margins. The topographical distribution of radioaerosol was expressed in terms of a penetration index, arbitrarily defined as the ratio of radioaerosol present in an outer $(\mathrm{O})$ region to the amount present in the inner (I) region of the lung expressed relative to krypton: $(\mathrm{O} / \mathrm{I}) \mathrm{Tc} /(\mathrm{O} / \mathrm{I}) \mathrm{Kr}$. Deposition of the radioaerosol within the lungs was counted by anterior and posterior scintillation counters located within collimators with a wide angle field of view. Clearance of deposited radioaerosol from the lungs was monitored by taking counts half hourly for the initial six hour period, with a final count at 24 hours to determine alveolar deposition. During the high frequency oscillation study 30 minutes in every hour were spent on the oscillator with scintillation counts before and after each period. The initial high frequency oscillation period began within 20 minutes of inhaling the radioaerosol. Any coughs made during the six hour observation period were recorded.

The results were compared by Wilcoxon's test for paired differences as the number of subjects studied was small.

\section{Results}

Results of lung function tests, radioaerosol inhalation flow rate, alveolar deposition, and penetration index did not differ significantly between the control and high frequency oscillation study days (table). This confirmed that any difference noted between the two days were due to changes in mucociliary clearance.

The mean tracheobronchial clearance curves for 


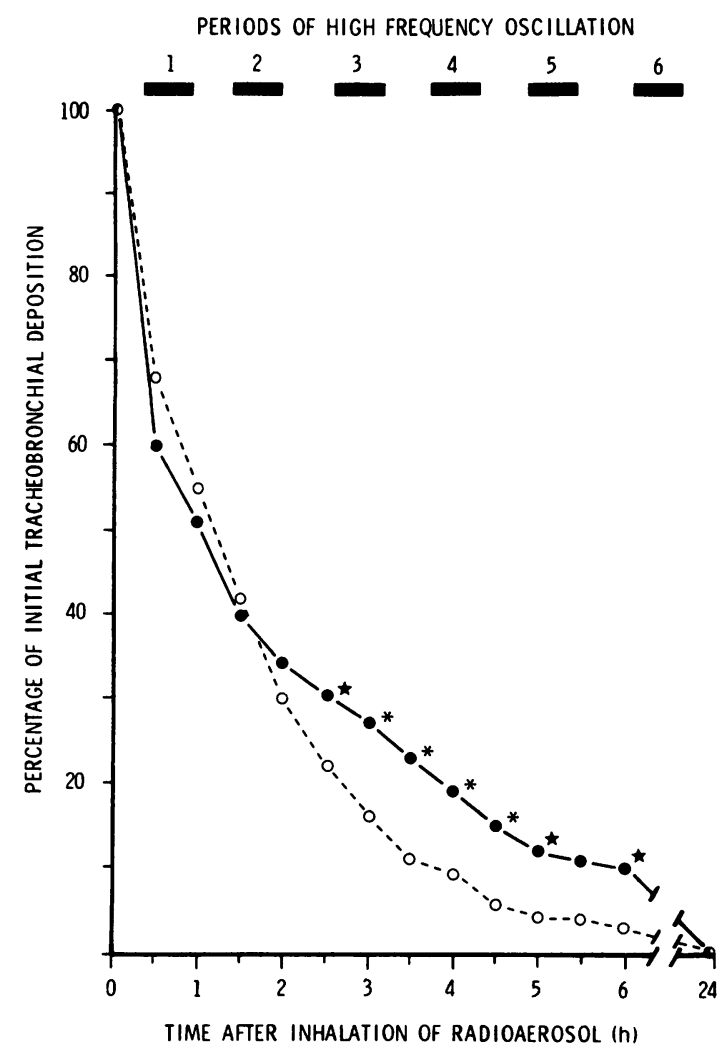

Fig 2 Mean tracheobronchial clearance curves over 24 hours with and without oral high frequency oscillation in seven normal subjects, expressed as the percentage of initial tracheobronchial deposition of radioaerosol.

the control and high frequency oscillation runs are shown in figure 2. Between 3 and 4.5 hours mucociliary clearance with high frequency oscillation exceeded control values by about $10 \%$ ( $p<$ 0.05 ). There was an overall increase in mucociliary clearance during high frequency oscillation over the control mucociliary clearance-expressed as the mean time taken to eliminate $90 \%$ of deposited radioaerosol from the tracheobronchial tree (T90). This fell from 4 hours 50 minutes $(1 \mathrm{~h} 52$ min-6 h $50 \mathrm{~min})$ in the control run to $3 \mathrm{~h} 43 \mathrm{~min}(2 \mathrm{~h}$ $28 \mathrm{~min}-5 \mathrm{~h} 54 \mathrm{~min}$ ) during the high frequency oscillation run $(\mathrm{p}<0.05)$.

\section{Discussion}

Clearance of radioaerosol from the lungs is intimately related to the initial site of deposition; under the same condition particles in the proximal airways will be cleared faster than those deposited in the more distal, ciliated airways. Factors that can affect the initial topographical distribution of the radioaerosol within the lungs are: $(a)$ the physical properties of the aerosol, $(b)$ its mode of inhalation, and $(c)$ airway patency. "In this study $(a)$ and $(b)$ were strictly controlled and $(c)$ did not vary between runs. Such controlled conditions resulted in similar initial deposition patterns of radioaerosol within our group, as shown by the similarity in the values of alveolar deposition and penetration index. Thus the differences in the tracheobronchial clearance of the deposited particles are a reflection of the effects of oral high frequency oscillation on the mucociliary escalator.

This study shows that oral high frequency oscillation improves lung clearance in normal subjects. Its overall effect was to reduce T90 by $23 \%(p<0.05)$, with the main effect occurring between 3 and 4.5 hours $(p<0.05)$. This timing suggests that oral high frequency oscillation may act in the distal airways, ${ }^{2}$ where cough is an ineffective clearance mechanism.

The conflicting reports of the effects of high frequency ventilation on mucociliary clearance probably reflect the diversity of the system and the techniques used in their application. King and colleagues ${ }^{4}$ found that external chest wall compression increased tracheal mucus velocity over a wide range of frequencies. Klain $e^{2} a^{5}$ reported that high frequency jet ventilation at $1.6 \mathrm{~Hz}$ also increased tracheal mucus velocity. They suggested, however, that mucus distal to the jet orifice may be driven into the peripheral airways, although pathological studies in dogs of lung parenchyma after high frequency jet ventilation have shown no mucus plugging or hypersecretion. ${ }^{12} \mathrm{~A}$ recent abstract reports the beneficial effect of high frequency jet ventilation in clearing secretions in patients with chronic airflow obstruction. ${ }^{7}$ A comprehensive study by McEvoy, ${ }^{\circ}$ however, examined regional lung clearance of radioaerosol and tracheal mucus velocity during high frequenty oscillation at $20 \mathrm{~Hz}$ in anaesthetised dogs. The oscillations in this study were sine wave, but end expiratory airway pressure was maintained above zero, so that there was no truly negative pressure phase to these oscillations. They reported copious mucus secretions within the trachea in all animals but, paradoxically, appreciably slower isotope clearance from all lung regions than in control studies performed during volume cycled ventilation. Total minute ventilation was unaffected. It therefore seems that high frequency ventilation may have a definite but varied effect upon mucociliary clearance. The present study suggests that oral high frequency oscillation is effective at least in the healthy, awake, spontaneously breathing human subject.

The mechanisms by which oscillations may 
improve mucociliary clearance are unclear. There are several possibilities: a direct or mechanical effect on mucus characteristics, altered mucus production, and a change in ciliary beating.

King's studies ${ }^{4}$ showed total minute ventilation to depend on actual air movement within the trachea. The waveform produced during external chest wall compression had a sharp expiratory phase, which may have exerted an effect by moving mucus up the trachea physically or by altering mucus viscoelasticity. In subsidiary studies oscillations within a mucus lined tube led to progressive reduction in mucus viscoelasticity with frequency. ${ }^{4}$ Other workers have shown that the crosslinking within the gel structure of mucus influences the effectiveness of mucociliary coupling. They suggest that optimum coupling occurs with mucus of intermediary crosslinking density. ${ }^{13}$ With increasing frequency viscoelasticity continues to fall as crosslinking within the gel is reduced further. At a critical level this may reduce the integrity of the mucus blanket and lead to deterioration in mucociliary clearance. Such an effect is a possible explanation of the findings of McEvoy. ${ }^{6}$ There are no data on mucus secretion due to high frequency ventilation, but high frequency oscillations are known to increase vagal discharge, ${ }^{14}$ and this in turn may alter submucosal gland secretion, which increases with acetylcholine..$^{15}$

Mammalian cilia beat at frequencies of 10 $15 \mathrm{~Hz}{ }^{15}$ King's study in dogs showed a striking frequency dependence of total minute ventilation, which peaked at $13 \mathrm{~Hz}^{4}$ It was suggested that the cilia may have been stimulated directly, although the flow rates during this study were sufficient to precipitate waves within the mucus at the gas liquid interface. ${ }^{16}$ If these waves occur at a frequency close to that of the beating underlying cilia then mucociliary coupling may be improved. In a study of nasal mucociliary transport during nasal high frequency oscillation we have shown a similar though weak relationship of mucociliary clearance to frequency. ${ }^{17}$

In this study we have imposed sine wave oscillations on normal tidal breathing. These oscillations had a mean pressure of zero at velocities below that known to cause waves within the mucus. ${ }^{17}$ The most likely explanation for the favourable effect of high frequency ventilation on mucociliary clearance with our technique would seem therefore to be some alteration in mucus viscoelasticity. We are unable to comment on any neurohumoral effect of high frequency oscillation either on the production of mucus or on ciliary beat frequency. ${ }^{18}$

In conclusion, oral high frequency oscillation influences lung mucociliary clearance favourably in normal subjects when delivered by a simple mouthpiece. Although this technique does not allow assessment of regional clearance, the pattern of clearance suggests that oral high frequency oscillation may be effective in the peripheral airways, which are thought to be inaccessible to the effects of coughing. This preliminary study was confined to normal subjects. Further studies are required to confirm these observations and study the effects of oral high frequency oscillation on patients with excessive sputum production, for whom this technique might be of practical benefit both in hospital and at home.

\section{References}

1 Pavia D, Bateman JRM, Clarke SW. Deposition and clearance of inhaled particles. Bull Europ Physiopath Respir 1980;16:335-66.

2 Sutton PD, Pavia D, Bateman JRM, Clarke SW. Chest physiotherapy: a review. Eur $J$ Respir Dis 1892; 63: 188-201.

3 Sturgess JM, Palfrey AJ, Reid L. Viscosity of bronchial secretions. Clin Sci 1970;38:145-56.

4 King M, Phillips DM, Gross V, Vartian V, Chang HK, Zidulka A. Enhanced tracheal mucus clearance with high frequency chest wall compression. Am Rev Respir Dis 1983; 128:511-5.

5 Klain $M$, Keszler $\mathrm{H}$. High frequency jet ventilation prevents aspiration. Crit Care Med 1980;8:242.

6 McEvoy RD, Davies NJH, Hedenstierna G, Hartman MT, Spragg RG, Wagner PD. Lung mucociliary transport during high frequency ventilation. Am Rev Respir Dis 1982;126:452-6.

7 Rickel RL. Clinical application of high frequency jet ventilation in COPD patients. In: Carlon CG, Howland RS, eds. Proceedings of International Symposium on High Frequency Ventilation. New York: Sloan Kettering Cancer Centre, 1983:134.

8 George RJD, Winter RJD, Johnson MA, Slee IP, Geddes DM. Oral high frequency ventilation by jet or oscillator reduces minute ventilation in normal man. Thorax 1984;39:234-5 (abstract).

9 George RJD, Winter RJD, Flockton SJ, Geddes DM. Ventilatory saving by external chest wall compression (HFCWC). Thorax 1984;39:235 (abstract).

10 Pavia D, Sutton PD, Agnew JE, Lopez-Vidriero MT, Newman SP, Clarke SW. Lung mucociliary transport in man. In: Cumming G, Bonsignore G, eds. Cellular biology of the lung. New York: Plenum, 1982:205-23.

11 Agnew JE, Pavia D, Clarke SW. Airway penetration of radioaerosol: an index of small airway function. Eur $J$ Respir Dis 1981;62:235-55.

12 Keszler M, Klein R, McClellan L, Nelson D, Platt M. O Effects of conventional and high frequency jet ventilation on lung parenchyma. Crit Care Med 1982; 10:514-6.

13 Man GCW, Man FP, Kappagoda CT. Effect of high frequency oscillating ventilation on vagal and phrenic nerve activities. J Appl Physiol 1983;54:502-7.

14 Lopez-Vidriero MT. Airway mucus: production and composition. Chest 1981;80, suppl:799-804.

15 Rutland J, Cole PJ. Non-invasive sampling of nasal cilia for measurement of beat frequency and study of ultrastructure. Lancet 1980;ii:564-5. 
16 Clarke SW, Jones JG, Oliver DR. Resistance to twophase gas-liquid flow in the airways. J Appl Physiol 1970;29:464-71.

17 George RJD, Moore-Gillon Victoria, Geddes DM. High frequency oscillations improve nasal mucociliary clearance. Lancet 1984;ii:10-2.

18 Foster WM, Bergofsky EH, Bohning DE, Lippmann M, Albert RE. Effect of adrenergic agents and their mode of action on mucociliary clearance in man. $J$ Appl Physiol 1976;41:146-52.

\section{Book notices}

Measurement in Clinical Respiratory Physiology. Gabriel Laszlo and Michael F Sudlow. (Pp 337; \$60.) Academic Press. 1983.

This is designed to be used as a practical handbook, by doctors and technicians employed in a respiratory function laboratory. To achieve their objective the editors have invited contributions from practising clinical physiologists. Many chapters are enhanced by accurate descriptions of equipment and techniques, which will facilitate better clinical measurement in patients, often overawed by the plethora of equipment in modern laboratories. The key references and a well thought out index are invaluable. For a laboratory handbook the chapters written by technical personnel are particularly helpful. The theoretical physiology is often a repetition of that available elsewhere. The book falls into two parts discussing, firstly, instrumentation and, secondly, the assembly of equipment for specific purposes. No attempt has been made to describe all the available lung function tests. The editors offer a review of standard techniques together with those in areas of growing importance-for example, inductive plethysmography, non-invasive blood gas monitoring, assessment of respiratory muscle power, and sleep studies. Silverman's chapter on respiratory function testing in infancy and childhood is a welcome inclusion. This book is original and a useful addition to the library of any respiratory physiology department.-RMC
Cancer of the Esophagus in 1984. R Giuli. (Pp 425; \$40.) Organisation for Statistical Studies of Diseases of the Oesophagus. 1984.

This book is an account of the first congress of the International Organisation for Statistical Studies of Diseases of the Oesophagus (OESO). Its editor, Robert Giuli, founded OESO in 1979 with the purpose of accumulating information relating to the understanding, diagnosis, and management of carcinoma of the oesophagus. Specialists from many disciplines have come together from 23 different participating countries to supply data, have it put on computer, and then have it statistically analysed. At the back of the book are 24 pages of such data and conclusions that demonstrate the potential value of this type of study. Unlike those from personal series the data are free from bias and this is probably the single most important feature of this study. The reader is free to form his own conclusions. The main body of the book is devoted to the proceedings of the conference, which was in itself unique. After analysis of the data OESO met to formulate a series of questions, on which experts from all over the world, most of whom were not members of OESO, were invited to give their opinion. It provides a most interesting collection of attitudes of some highly respected workers in the area of oesophageal disease. This book will be enjoyed by a limited number of people with a major interest in oesophageal disease, but cannot be recommended as vital reading for a postgraduate student. It would, however, be a worthwhile addition to any medical library as the vast amount of data, conclusions, and opinions make it a unique reference volume on its subject.-KMP 